\title{
Autonomy as a property that characterizes organisms among other multicellular systems
}

\section{La autonomía como \\ una propiedad que caracteriza a los organismos frente a otros sistemas multicelulares}

\author{
ARGYRIS ARNELLOS ${ }^{a}$, \\ KEPA RUIZ-MIRAZO ${ }^{\mathrm{a}, \mathrm{b}}$ \\ ALVARO MORENO ${ }^{\mathrm{a}}$ \\ ${ }^{a}$ IAS-Research Centre for Life, Mind and Society - \\ Department of Logic and Philosophy of Science. \\ ${ }^{b}$ Biophysics Unit (CSIC-UPV/EHU) \\ University of the Basque Country (Spain)
}

\begin{abstract}
Biology is full of examples of multicellular (MC) systems which may demonstrate some organism-like properties but not all of them. Thus, it remains unclear if and when such systems should be considered as MC organisms, parts of organisms or groups of organisms. We suggest the notion of autonomy as a possible candidate to ground conceptually MC organisms and distinguish them from other forms of multicellularity. Considering unicellular systems as autonomous organisms on the basis of the functional integration required for their metabolic organization, we argue that MC systems should be also identified as autonomous, but on the basis of exhibiting a special kind of functionally integrated and differentiated developmental organization, which unfolds through a self-constructed set of mechanisms regulating the highly plastic processes that bring about their own constitution as such MC entities.
\end{abstract}




\author{
KEYWORDS \\ AUTONOMY, ORGANISM, MULTICELLULARITY, FUNCTIONAL INTEGRATION, \\ FUNCTIONAL DIFFERENTIATION, DEVELOPMENTAL CONSTRAINTS, EPIGENE- \\ TICS, SIGNALING NETWORKS
}

\begin{abstract}
RESUMEN
La biología está llena de ejemplos de sistemas multicelulares que pueden mostrar algunas propiedades de organismos, pero no todas. De este modo, no está muy claro si estos sistemas deben ser considerados como organismos multicelulares y cuándo deben serlo. Aquí sugerimos que la noción de autonomía es un candidato posible para fundamentar conceptualmente los organismos multicelulares y para distinguirlos de otras formas de multicelularidad. Considerando a los sistemas unicelulares como organismos autónomos sobre la base de la integración funcional requerida para su organización metabólica, argüimos que los sistemas multicelulares deben ser también identificados como autónomos, pero sobre la base de que exhiben un tipo especial de organización del desarrollo funcionalmente integrada y diferenciada, la cual se despliega a través de un conjunto auto-construido de mecanismos que regulan los procesos enormemente plásticos que dan lugar a su propia constitución como tales entidades multicelulares.
\end{abstract}

PALABRAS CLAVE

AUTONOMÍA, ORGANISMO, MULTICELULARIDAD, INTEGRACIÓN FUNCTIO-

NAL, DIFERENCIACIÓN FUNCTIONAL, CONSTRICCIONES DEL DESARROLLO, EPIGENÉTICA, REDES DE SEÑALES

\title{
I. INTRODUCTION
}

CONTEMPORARY ATTEMPTS TO DEFINE biological individuality are based either on physiological and genetic characteristics (see e.g. Santelices 1999), on the cooperative/competitive behaviors of the entities involved (e.g. West and Kiers 2009; Strassmann and Queller 2010), on evolutionary concepts, like fitness and adaptation (e.g. Queller and Strassmann 2009; Folse $3^{\text {rd }}$ and Roughgarden 2010) or on mixed approaches that favor specific aspects of functional integration, such as germ-soma separation (e.g. Buss, 1987; Maynard Smith and Szathmáry 1995; Michod 2007), resulting in cohesive or policing mechanisms, so that potential conflict among the constituting units is minimized (e.g. Frank 2003; Godfrey-Smith 2009).

But each of these aspects does not apply in all cases un-problematically. For instance, physiological unity is not present in every organism and genetic relatedness is not strictly necessary for high cooperation, while genetic heterogeneity is not always a threat to multicellular integrity (Folse $3^{\text {rd }}$ and Roughgarden 2010). In many cases potential cooperation does not linearly transform 
into actual cooperation, and potential for low conflict does not mean actual high integration or even actual low conflict (Strassmann and Queller, 2010). Besides, there are cases of discordant selection, where selection operating at a lower level may act against the selection at a higher level, even if the alignment and export of the fitness interests of the component units of an organism could also result in adaptation at the level of the (multicellular) organism (Gardner and Grafen 2009; Folse $3^{\text {rd }}$ and Roughgarden 2010). However, adaptation is not an easy notion to explain, and is often taken to be demonstrated at a given level of selection, thus resulting in different answers when it is the product of group selection or of multiple levels of individual selection (Okasha, 2006). In summary, there is a plurality of views and various difficulties around the problem of defining the biological individual and there are several criteria, whose combination generates multiple different verdicts that do not necessarily overlap and which fail to accommodate many examples we can think of in real biology (Clarke 2011).

And yet, the clarification of the concept of an 'individual organism' is an important philosophical and scientific problem, not only because the idea of organism has played a key role in the history of biology (as a central part of biological explanations -i.e., as the locus of mechanisms, of adaptations, of selective-evolutionary dynamics); but also because, as it is argued in RuizMirazo and Moreno (2011), without a strong idea of organism it would be very difficult to provide a naturalized account of other fundamental concepts like functionality, agency, autonomy, genetic information, etc.

Accordingly, we believe that a more comprehensive approach to biological individuality is needed, and we suggest the notion of 'autonomy' as a possible candidate for such an inclusive or comprehensive approach. Autonomy places the individual organism at the centre of the stage and emphasizes that any biological individual organism needs to realize the property of maintaining itself as a metabolic system. Autonomous systems are not independent from their surrounding, they critically rely on diverse features of the environment (e.g.: general physico-chemical conditions for viability, energetic and material availability, etc.) but they continuously generate and regenerate all the constraints and mechanisms upon which the use and management of those resources is based. Therefore, there is a continuous interplay between the organization of processes constituting a relatively stable identity (or 'self'), and the interactions with the environment that this identity triggers and supports, which are crucial for its maintenance. So autonomy must be conceived in terms of a particular connection, or even collaboration with external systems. But, as in the case of metabolism, it is impossible to talk of autonomy without the specification of some form of self-constructed, individual identity. On the other hand, biology shows many collective forms and groupings of entities, which may resemble 
several composite forms of autonomy, but it is not clear whether those groupings should be considered as full-fledged autonomous individuals or as just colonial systems. Then, assuming that unicellular entities are autonomous organisms, the question to address would be what sorts of MC systems, if any, meet equivalent requirements and can therefore be regarded, themselves, as organisms -or, as higher order autonomous organizations (Ruiz-Mirazo and Moreno 2011).

With this aim, taking into account the main results of current biological investigations on the developmental processes of different types of MC systems, we attempt to examine whether the concept of autonomy can account for other functionally diverse but at the same time integrated forms of collective associations of biological entities and processes. In other words, we shall suggest when and how would it be possible to discern whether a group of cells is just gathering together temporarily to improve their overall fitness, or irreversibly becoming part of a higher-order autonomous entity. Certainly, the creation of a higher order full-fledged autonomous entity requires some kind and degree of functional integration, as an autonomous system's creation is not possible without a stronger subordination of the constitutive elements to the new functional requirements of the emerging global individual (Ruiz-Mirazo and Moreno 2011). Accordingly, we suggest that with respect to MC collections, autonomy should be analyzed following at least a set of criteria related to the overall developmental coordination of the collection, the presence of differentiated cell types and the regulation of their development, and their respective kind and degree of functional integration necessary for the development and maintenance of the organismal level (the level of the whole).

On those lines, in section 2 we discuss that, from an organizational point of view, MC organisms should be identified by a set of criteria related to the developmental mechanisms used by the collection of cells to coordinate their differentiation pathways, in a way that the robust maintenance and potential reproduction of the whole developing system is ensured through an emergent functionally integrated organization. In section 3 we examine cases of advanced bacterial multicellularity and of early eukaryotic multicellularity, where overall developmental regulation is not that evident and a very limited degree of cellular differentiation is at place, and we compare them with a case of early metazoans. In section 4 we argue that although the former cases exhibit substantial coordination and cohesion (and functional integration surely at other organizational levels), they do not qualify as autonomous entities, since full-fledged autonomy at the $\mathrm{MC}$ level involves a special kind of regulatory control that provides the potential for both functional diversification and functional integration required for the proper and reliable unfolding of a process of development. 


\section{ORGANISMS IN AN EVOLUTIONARY AND IN AN ORGANIZATIONAL CONTEXT}

Within the modern synthesis, an organism is considered as the central point of reference for evolution by natural selection (NS). According to that evolutionary theoretical framework, individual organisms could be all those entities (genes, cells, groups, species) on which natural selection operates, inducing the differential survival and reproduction of the respective population. The Darwinian tradition proposes a natural explanation for the design of any organism based on the mechanism of NS. From that conception, in which the unit of evolution (or unit of selection) is what really matters, fitness and its maximization are normally taken as the fundamental criterion to define organisms (Gardner 2009). Gardner argues that fitness-maximization is the key design principle that explains how natural selection solves the problem of adaptation, that is, the packaging of parts into units of common purpose (be them organisms or watches) (Gardner and Grafen 2009). Accordingly, an organism is a whole whose parts are all under selection to maximize its fitness.

However, there is a fundamental difference between living organisms and artificial systems, regardless of their apparent operational or global similarities: whereas the watch is formed by fixed components, fabricated beforehand and later assembled, in the organism the parts are formed for and from the others, some parts actually producing the others. The main issue in this difference is that in living organisms, there is a constitutional relation among the parts to form an organization. That is why, for the Darwinian tradition the identification of watch and organism (even regarding only contrivance and relation among parts) is not problematic, whereas from the organizational point of view a distinction should be made. This distinction implies that there is a difference between explaining 'function' as deriving from the concept of organization, and as deriving from adaptation. And that is also the main reason why Darwin's theory did not solve all the objections to mechanistic approaches, especially regarding the lack of a complete, satisfactory account of the intrinsic functioning of organisms.

From an organizational perspective, an organism is functionally integrated in the sense that it maintains a material dynamic organization, which plays a fundamental causal role in the generation of the structural constraints that actually make it possible (Moreno et al. 2011). However, the notion of 'functional integration' is difficult to be operationalized, as it implies the coordination among complex dynamical parts, which is exhibited in different degrees and types in each ensemble. One could even say that everything we find in nature is functionally integrated, in some degree and in some respect (Wilson 2000; Clarke, 2010). Slime molds are functionally integrated but not in the same degree as an animal; the organs of a higher animal are causally and hence functionally integrated but so are the members of a good music band. Therefore, there 
is a need for specification of the type (the strength, plasticity, complexity...) of the interactions between parts in order for them to qualify as members of a 'single functionally-integrated' whole -i.e. of a higher-order autonomous organization.

Dealing with the problem of MC organisms, in this paper we focus on how collections of cells are able to repeatedly develop into such highly organized and integrated entities. Development is here considered as a process that makes possible the generation of a MC system in which different types of cells perform different tasks, and in which all of them come from a single, fertilized mother cell. Now, it should be noted that, in general terms (keeping the organizational perspective), a material structure is considered as functional if it is generated within a system and it operates as part of a network of constraints that contribute differently to the development and self-maintenance of that system at the level of the whole (Mossio et al. 2009). Therefore, in a MC system, in particular, a material structure would be considered as functional if it is created within the system and if it operates so as to induce such cellular differentiations, the result of which will contribute to the development and self-maintenance of the system at the level of the whole. Accordingly, the kind of functional integration that matters for our purposes should imply inductive and regulatory control on the fate of the cells during the process of cellular differentiation: the MC system drives the generation of its unicellular parts but, also and more importantly, regulates its development in order to be able to re-construct the dynamic relations between those parts, i.e. to re-construct its own MC organization. Thus, the appropriate descriptive level to frame our problem is in the context of systems that comprise a diverse network of cell-cell interaction mechanisms and display a strong interweaving between their ontogenetic development and their subsequent reproduction. And the idea is to do so from the point of view of autonomy: i.e., of the self-determination capacities of the MC system involved. Therefore, as we shall elaborate below, we examine the developmental processes of MC systems by focusing on the characteristic properties of intercellular constraints ('signals') that are considered as functional because they are generated within the system, and they are participating in a collective network of regulatory mechanisms that are, in turn, capable of modulation of intracellular epigenetic mechanisms affecting the fate of cellular differentiation during development, thus bringing about a higher-order functional integration at the $\mathrm{MC}$ level.

So in the following section we will take a closer look at the process of development of three MC systems: the cyanobacterium Nostoc.punctiforme and the green algae Volvox.carteri, as a case of advanced bacterial and early eukaryotic MC system, together with the echinoderm Strongylocentrotus.purpuratus (a sea urchin): a metazoan MC system. The MC systems chosen to be examined here are all constituted by genetically homogeneous cells and they 
implement complex organizations with a relatively high degree of cohesion. Hence, at least phenotypically speaking, they are potential candidates to be characterized as MC organisms.

\section{DEVELOPMENTAL REGULATION IN THREE MULTICELLULAR SYSTEMS}

\section{III.1. DEVELOPMENTAL REGULATION IN ADVANCED BACTERIAL AND EARLY EUKARYOTIC $M C$ SYSTEMS}

Nostoc punctiforme is a filamentous photosynthetic and diazotrophic cyanobacterium with two cell types: ${ }^{1}$ vegetative cells, which are responsible for photosynthesis, and heterocysts, which are responsible for nitrogen fixation. The nitrogen products are passed along to the photosynthesizing cells and, in turn, photosynthetic cells transfer to heterocysts several metabolites necessary for their operation. Differentiation takes place at a frequency of about $8 \%$ of the total cells (Meeks et al. 2002), producing a semi-regular pattern of morphologically and metabolically different cell types. Several models have been proposed to explain the semi-regular pattern of heterocyst development (see Kumar et al. 2010 for details). All cells in the filament detect the signal to differentiate (nitrogen deprivation) but only some of them respond to it, leading to a biased initiation process of differentiation. The earliest signal of nitrogen limitation triggers the activation of the global nitrogen regulator, NtcA, in all the cells that are at the appropriate cell stage. Activated NtcA then functions as a transcriptional activator of other inducing or suppressing proteins of heterocyst differentiation, in a way that only a single heterocyst is present at a given site in the filament. This can be visualized as the result of a competitive interaction between an activator $(H e t R)$ and an inhibitor (PatS) of heterocyst development. HetR is an intracellular activator of heterocyst development and PatS is the diffusible inhibitor (see Kumar et al. 2010 for details). Cells in the appropriate stage initiate development by synthesizing HetR. High HetR activity induces cell differentiation, whereas high PatS decreases HetR and leads to regression. HetR promotes its own synthesis (through autocatalysis)

1 In $N$. punctiforme the vegetative cells can also develop into akinetes, spore-like structures that are more resistant to cold and desiccation conditions, and into hormogonium filaments, which lack heterocysts, have smaller size and a slow gliding motility, used for short-distance dispersal. The development of akinetes does not seem to involve any intercellular signaling but it is strictly triggered by environmental inputs. Hormogonium development will result in one cell type in the filament and, again, this seems to be triggered by environmental signals followed by multiple independent (intracellularly controlled) cell divisions for each one of the cells (see Meeks et al. 2002 for details). It is for those reasons that we do not consider these modalities in our description of $N$. punctiforme. 
but also the production of PatS. On the contrary, PatS suppresses HetR. In neighbouring cells, the entry of PatS will prevent the formation of HetR. In more distant areas, diffusion of PatS may not be sufficient, so new centres of activation can be formed. ${ }^{2}$

A careful analysis of the details of heterocyst development (see e.g. Meeks et al. 2002; Kumar et al.2010; Maldener and Muro-Pator 2010) reveals that the signaling network which guides the development of a differentiating cluster of cells into one heterocyst at any developmental site in the filament operates under a single constraint (PatS concentration) at the collective level. There seems to be no generation of other compounds/structures (i.e., no synthesis of any morphogen or some other kind of signal in the cells where HetR is suppressed by PatS), which acts intercellularly on the phenotypic traits and organization of the different cell that produced PatS -or on any other neighbouring cell. In addition to that, heterocysts undergo terminal differentiation, as they lose the ability to divide. In fact, whether a vegetative cell can be turned into a proheterocyst is strictly connected to its life-cycle stage (Meeks et al. 2002). Now, this implies a mechanism of differentiation that remains strongly coupled to the core metabolic requirements of the process of growth and division of the vegetative cells. In addition, heterocysts development is a terminal event because they 'sacrifice' their ability to reproduce in order to provide surrounding vegetative cells with combined nitrogen. Moreover, there is a $24 \mathrm{~h}$ delay in the growth process of the filament after the development of functional heterocysts, which is a result of the downregulation of genes related to vegetative growth and division (Christman et al. 2011). Those two facts indicate that cell division and cell differentiation cannot be modulated outside of the core metabolic context. On the contrary, they imply a mechanism of the developmental regulation of differentiation that remains strongly coupled to the metabolic requirements of the vegetative cells.

Volvox carteri is a eukaryotic MC system constituted by unicellular algae and has a developmental process that results in spheroid adults with two cell types: large reproductive cells (gonidia) and small motile somatic cells. Somatic cells do not divide but continue beating their flagella, thereby providing the group with a capacity to swim. The rest of the cells in the group (the germ cells) divide and produce progeny. Complete germ-soma separation derives from the fact that, in Volvox carteri, germ cells directly become reproductive gonidia.

2 The developmental direction is also influenced by ancillary inducing and suppressing signals. However, those signals are always acting intracellularly and downstream the main activator and inhibitor, and independently within each cell. Therefore, they are irrelevant to our analysis and will not be discussed here. 
A healthy culture of V. carteri will cleave 11 times and will result in division of labor among (approximately) 2000 somatic cells and 16 germ cells. During embryogenesis some of the cleavage divisions are asymmetric, producing large/small sister-cell pairs (Kirk 2005). At the end of embryogenesis the volume of the gonidial initials is about 30 -fold larger than that of the somatic initials. However, at that stage, cells are only different in size. Then, by a still unknown mechanism, the size of each sister cell leads to the activation of either a somatic or germline program (Kirk 2005). Thus, small cells develop as biflagellate somatic cells for motility, biosynthesis of the extracellular matrix, and phototaxis, and large cells develop as non-motile, germ cells specialized for growth and reproduction.

In the developmental process of V. carteri (see Kirk 1998; 2005 and Hallman 2011 for details) the initiation of somatic or gonidial developmental process is explicitly dependent on the size of each cell and cellular differentiation is achieved by intracellular cell fate specification. Specifically, V.carteri cells that are below the threshold diameter of $8 \mu \mathrm{m}$ at the end of cleavage will activate the somatic-cell program of differentiation, while cells above that threshold activate the gonidial program. And this happens even if all of the cytoplasm that they contain is cytoplasm that would normally have been found in somatic cells. In addition, the way $V$. carteri achieves its complete germ-soma separation prohibits any further flexibility and variability in the genotype-phenotype mapping, as discussed thoroughly by Nedelcu and Michod (2004). Thus, in V.carteri-even more explicitly than in $N$. punctiforme, given the complete germ-soma separation of the former-cell division remains either totally decoupled (in somatic cells) or strongly coupled (in germ cells) to cell growth and global system reproduction. Therefore, we can conclude that the development of cellular differentiation in $V$. carteri takes place independently of any constraining signaling structures produced from other cells in this MC system. Furthermore, as in the $N$. punctiforme case, development in $V$. carteri is also strongly coupled to the core metabolic requirements of the processes of growth and division, preventing potential mechanisms for meta-cellular modulation of the developmental process and the adaptive evolution of further cell differentiation patterns.

\section{III.2. DEVELOPMENTAL REGULATION IN METAZOANS: THE CASE OF A SEA URCHIN}

The sea urchin (SU) Strongylocentrotus purpuratus is a small invertebra$\mathrm{te}^{3}$ that belongs to the echinoderm phylum. Although it is a relatively simple

3 The sea urchin is an excellent system to study fundamental mechanisms underlying the development of metazoan embryos, since it is relative simple, and its genome has been sequenced. The construction of its endomesoderm gene regulatory network (GRN) pertaining to both intra- and inter-cellular signals up to 30 hours post-fertilization is currently the largest and 
metazoan, it shows a very interesting developmental process leading to differentiated tissues and organs. Sea urchin embryos develop into free-swimming pluteus larvae consisting of only five major tissues in about 3 days. The period of cleavage lasts almost 9 hours post fertilization (hpf) and the embryo hatches from its fertilization membrane at about $18 \mathrm{hpf}$. Mesenchyme blastula begins at 24hpf. By the time gastrulation begins (around 27-30 hpf) skeletogenic, mesoderm, anterior and posterior endoderm and ectoderm cell lineages have been specified.

One of the most interesting features of the SU development (see Peter and Davidson 2010 for details) is the intercellular interactions that dynamically modulate key aspects of the process. The development of SU is characterized by signals (maternally provided or/and created within the system) that constrain the organization of other cells, so that their developmental fate is appropriately specified and ensured (initialization of the development of the endomesoderm; timely separation between mesoderm and endoderm specification and between anterior and posterior endoderm specification, initiation of gastrulation, etc). And such a kind of intercellular signaling continues throughout the developmental process, at least up to the pluteus larva stage. As a matter of fact, with the continuous increase in the number and links among these intercellular signals, the $S$. purpuratus embryo develops an amazing set of features and physiological and anatomical properties in just 3 days. There is a highly elaborated set of intercellular and intracellular signals that endows the embryo with an amazing capacity for regulating its own development. Indeed, cells in the SU embryo are continuously signaling to each other to ensure that tissues critical to survival of the embryo are present (Angerer and Angerer 2012).

There are three characteristic properties of these signals: a) they establish intercellular mechanisms that regulate the developmental process by triggering, activating and suppressing intracellular processes responsible for the specification of the developmental fates of the respective cell lineages and for the modulation of other intercellular mechanisms that will further regulate the developmental process; b) there are different combinations between intercellular constraining signals, which result in different types of intercellular mechanisms and consequently, in qualitatively different ways of developmental regulation; and c) the intercellular operation of these signals is uncoupled from the reproductive and self-maintaining intracellular processes of the cells whose development they regulate. More specifically, through the intercellular mechanisms that coordinate and regulate the embryo's developmental processes, firstly, the specification state of each cell lineage is spatiotemporally

most detailed network described in any embryo, which is constantly updated (for more details, check the website: http://sugp.caltech.edu/endomes/\#UpTo30NetworkDiagram). 
stabilized; and, secondly, the continuation of the specification process is uncoupled from the respective intercellular mechanisms -among other things because their characteristic/operational time scales are different. The previous three properties make the developmental process of S.purpuratus qualititively different, because there is an effective regulatory control system that operates intercellularly, at the level of the MC organization, and which autonomously coordinates its development. This regulatory control system consists of intercellular mechanisms sufficiently independent from the intracellular processes of the assembling units, and which can be varied without disrupting those more basic intracellular processes, but which are still able to be linked to parts of the cellular epigenetic mechanisms, modulating their operations. In other words, there is a dynamic decoupling between the regulatory control mechanism (or set of controlling subsystems) that act(s) intercellularly in the developmental process and the controlled processes of the intracellular epigenetic machinery, responsible for the implementation of the actual state of each cell lineage. This 'regulatory control system' constitutes an endogenously created set of specific functional signals that belong to the (newly developed) MC organizational level and it is through their constraining action that such a complex developmental process is effectively driven and stabilized. In addition, the set of developmental signals gets 'recursively' generated along the developmental process itself: that is, part of these intercellular signals constraining intracellular processes, which initiate and eventually determine the formation of the diverse cell lineages, also affect (by inducing or suppressing) the production of other intercellular signals which, in turn, will constrain the intracellular processes of other cells in the embryo, and so on and so forth.

In all, $S$. purpuratus shows a new developmental logic that coordinates cellular differentiation and integration processes, based on a regulatory control system which operates in a distinct hierarchical level. This hierarchical level is decoupled from the underlying metabolic, intracellular needs and is comprised by several intercellular mechanisms that determine the fate of different cell lineages, while allowing new possibilities of cell differentiation, and brings forth in this way a new domain of possible forms of $\mathrm{MC}$ organization. In the next section we briefly argue why this type of MC system with a higher-order complex regulatory control system, specifically applied to the control and regulation of its developmental activity, is a single functionally integrated and differentiated developmental unit, and should be conceived as a full-fledged autonomous organization. 


\section{Developmentally Regulated and functionally integrated MC ORgani- ZATIONS AS AUTONOMOUS SYSTEMS}

As we explained in the previous section, not all developmental MC systems constituted by genetically homogeneous cells exhibit the same kind and degree of functional diversity, plasticity and integration in their organization. MC systems like $N$. punctiforme and V.carteri, for instance, do not demonstrate a MC organization with the capacity to impose regulatory control over the epigenetic dynamics taking place in the cells. Of course, in both MC systems (Nostoc and Volvox) there are far-from-trivial cell-to-cell interaction processes necessary for their operational coordination (division of labor) and collective pattern generation or global behavior. As an example, in N. punctiforme there is a rich exchange of metabolites between vegetative cells and heterocysts, which is necessary to meet the needs of the two cell types. So, they do have intercellular mechanisms with a constraining effect on intracellular dynamics; however, these are not sufficiently diverse and recursive to open a new functional and hierarchical domain that could lead to highly integrated and differentiated developmental organizations. In other words, although there is cooperation among cellular entities, there is no an overall control system to coordinate and regulate development, ensuring its maintenance and reproduction and, thus, integrating these cells together as a robust entity and a unit of selection in its own right. Thus, from this theoretical standpoint, N. punctiforme and V. carteri should not be regarded as autonomous systems.

On the contrary, in S. purpuratus, there is an operational combination of different types of regulatory mechanisms acting intercellularly, and controlling the epigenetic intracellular processes, in a way that cellular differentiation is enhanced and immediately channeled into what could be considered a fullfledged functionally integrated organization. This form of organization provides the capacity for robust self-construction of the collective system, which, through an internally regulated developmental process, is able to reproduce itself, as well. More precisely, a set of intercellular material structures shaping developmental processes are endogenously created by the system (in a similar way as enzymes are endogenously produced by each cellular metabolism), so that they regulate, modify and control both self-production processes and processes of exchange with the environment. In other words, in surprisingly close analogy with a unicellular autonomous organism, this type of MC system becomes a functionally integrated entity: i.e., its dynamic organization plays a causal role in the generation of the material structures that actually make it possible. It is the production of those regulatory control mechanisms that will trigger off and regulate the development of the functional relations among its autonomous unicellular parts what turns the whole system into a self-maintaining 
and self-reproducing integrated organization, becoming itself autonomous, but at a different hierarchical level. This is essentially why $S$. purpuratus can be considered, from this perspective, a true MC autonomous system.

\section{Conclusion}

There might be an intuitive grasp on the properties that our common sense takes as important about organisms, but this fails to accommodate many examples observed in real biology. Then, a more careful and elaborate theoretical approach is needed to assess thoroughly the concept of organism: an approach in which the 'organizational-systemic' perspective complements the historic and collective/collaborative dimension. In this perspective, building upon the autopoietic conception (Maturana and Varela 1973), it has been suggested that unicellular systems with the capacity for self-construction, which are able to produce those constraints that ensure the maintenance (and eventually, the reproduction) of their organization, are already autonomous in a basic or minimal sense (Ruiz-Mirazo and Moreno 2004). Thus, at the unicellular level, a prokaryotic or eukaryotic cell, as an autonomous organism, implies a type of material organization in which its structural components (as 'parts') and the cell (as the 'whole') are interdependent, maintaining an intricate dynamic relationship. In other words, a cell is a functionally integrated entity because its dynamic organization plays a causal role in the generation of the functional structures that actually make it possible, that actually regulate the (molecular) development of its organization. According to a parallel line of argument, candidate MC systems, in order to become autonomous, must produce (as a result of the interactions among all the parts involved) a network of functional constraints that regulate the developmental processes of each of the differentiated parts in a highly reliable and reproducible way. And, indeed, biology shows that there are complex MC systems that achieve a full-fledged functionally integrated and differentiated organization precisely through the regulatory control on its developmental dynamics. These autonomous MC systems fully deserve to be regarded as organisms.

\section{ACKNOWLEDGEMENTS}

This work has been supported by grants from the Ministerio de Ciencia e Innovación FFU2009-12895-CO2-02, Ministerio de Economía y Competitividad FFI2011-25665 and Gobierno Vasco IT 505-10. Argyris Arnellos holds a Marie Curie Research Fellowship (IEF-273635). Authors would like to thank also the organizers of the first conference of the AIFIBI (Valencia, Spain, Nov. 
2012), where this work was presented, and Antonio Diéguez in particular, for the opportunity to share these ideas with the Ibero-American community of philosophers of biology and get insightful feedback from them.

\section{REFERENCES}

ANGERER, R.C., ANGERER, L.M., (2012) «Sea Urchin Embryo: Specification of Cell Fates». eLS John Wiley \& Sons Ltd, Chichester. doi: 10.1002/9780470015902. a0001513.pub3

BUSS, L. W. (1987). The evolution of individuality. Princeton University Press.

CLARKE, E. (2011). «The problem of biological individuality». Biological Theory 5:4, pp312-325

CHRISTMAN, H.D., CAMPBELL, E.L., MEEKS, J.C. (2011) «Global transcription profiles of the nitrogen stress response resulting in heterocyst or hormogonium development in Nostoc punctiforme». J. Bacteriology 193(24): 6874-6886.

FOLSE 3rd, H. J., and J. ROUGHGARDEN. (2010). «What is an individual organism? A multilevel selection perspective». The Quarterly review of biology 85, no. 4: 447-472.

FRANK, S. A. (2003) «Repression of competition and the evolution of cooperation». Evolution 57, no. 4: 693-705.

GARDNER, A. (2009) «Adaptation as organism design». Biology Letters 5(6): 861864

GARDNER, A., and A. GRAFEN (2009) «Capturing the superorganism: a formal theory of group adaptation». Journal of Evolutionary Biology 22, no. 4: 659671.

GODFREY-SMITH, P. (2009) Darwinian Populations and Natural Selection. OUP Oxford, March 26.

HALLMANN, A. (2011) «Evolution of reproductive development in the volvocine algae». Sex Plant Reprod 24: 97-112. doi: 10.1007/s00497-010-0158-4

KIRK, D.L. (1998) «Volvox: molecular-genetic origins of multicellularity and cellular differentiation». Developmental and cell biology series. Cambridge University Press, Cambridge.

, (2005) «A twelve-step program for evolving multicellularity and a division of labor». BioEssays 27: 299-310

KUMAR. K., MELLA HERRERA, A.R., GOLDEN, W.J. (2010) «Cyanobacterial Heterocysts». Cold Spring Harb Perspect Biol 2010. doi: 10.1101/cshperspect. a000315

MATURANA, H., and VARELA, F. J. (1973) De Máquinas y Seres Vivos -- Una teoría sobre la organización biológica. Editorial Universitaria S.A., Santiago de Chile. 
MAYNARD SMITH, J., and E. SZATHMÁRY (1995) The major transitions in evolution. New York: Freeman.

MEEKS, J.C., CAMPBELL, E.L., SUMMERS, M.L., WONG, F.C. (2002) «Cellular differentiation in the cyanobacterium Nostoc punctiforme». Arch Microbiol 178: 395-403

MICHOD R.E. (2007) «Evolution of individuality during the transition from unicellular to multicellular life». Proceedings of the National Academy of Sciences USA 104 (supplement 1): 8613-8618.

MORENO A, RUIZ-MIRAZO K, BARANDIARAN, XE (2011) «The impact of the paradigm of complexity on the foundational frameworks of biology and cognitive science». In Hooker CA, Gabbay DV, Thagard P, Woods J (eds) Handbook of the Philosophy of Science (Vols. 1-10, Vol. Philosophy of Complex Systems, pp. 311-333).

MOSSIO, M., SABORIDO, C. and MORENO, A. (2009) «An Organizational Account for Biological Functions», British Journal for the Philosophy of Science 60 (4): 813-841.

NEDELCU, A.M., MICHOD, R.E. (2004) «Evolvability, modularity, and individuality during the transition to multicellularity in volvocalean green algae». In: Schlosser, G., Wagner, G., (eds) Modularity in development and evolution. University of Chicago Press, pp 468-489.

OKASHA, S. (2006) Evolution and the levels of selection. Oxford University Press.

PETER, I., DAVIDSON, E.H., (2010) «The endoderm gene regulatory network in sea urchin embryos up to mid-blastula stage». Dev Biol 340(2): 188-199

QUELLER, D. C, and STRASSMANN, J. E (2009) «Beyond society: the evolution of organismality». Philosophical Transactions of the Royal Society B: Biological Sciences 364, no. 1533: 3143.

ROSSLENBROICH, B. (2008) «The theory of increasing autonomy in evolution - a new proposal for understanding macroevolutionary innovations». Biology \& Philosophy 24: 623-644.

RUIZ-MIRAZO K, MORENO A, (2004) «Basic autonomy as a fundamental step in the synthesis of life». Artificial Life 10(3):235-259

RUIZ-MIRAZO, K. \& MORENO, A. (2011) «Autonomy in evolution: from minimal to complex life». Synthese (2). doi:10.1007/s11229-011-9874-z.

SANTELICES, B. (1999) «How many kinds of individual are there?». Trends in Ecology \& Evolution 14, no. 4: 152-155.

STRASSMANN, J. E, and QUELLER, D. C (2010) «The Social Organism: Congresses, Parties and Committees». Evolution 64, no. 3: 605-616.

WEST, S. A, and KIERS, E. T (2009) «Evolution: What Is an Organism?». Current Biology 19, no. 23: R1080-R1082.

WILSON, J. (2000) «Ontological butchery: organism concepts and biological generalizations». Philosophy of Science 67: 301-311 
Argyris Arnellos es Marie Curie Research Fellow en el Departamento de Lógica y Filosofía de la Ciencia UPV/EHU, IAS Research Center for Life Mind and Society

Líneas de investigación:

Filosofía de la biología, sistemas autónomos y complejos, cognición y emoción.

Publicaciones recientes:

ARNELLOS, A. \& MORENO, A. (2012) «How functional differentiation originated in prebiotic evolution». Ludus Vitalis XX(37): 1-23.

ARNELLOS, A., BRUNI E., L., EL-HANI C. \& COLLIER, J. (2012). «Anticipatory Functions, Digital-Analog forms and Biosemiotics: Integrating the tools to model Information and Normativity in Autonomous Biological Agents», Biosemiotics, 5(3): 331-367.

Dirección electrónica: argyris.arnellos@ehu.es

Kepa Ruiz-Mirazo es Investigador Permanente del Departamento de Lógica y Filosofía de la Ciencia (UPV/EHU) y de la Unidad de Biofísica (CSIC-UPV/EHU).

Lineas de Investigación:

Origen de vida, filosofia de la biologia, sistemas complejos, modelos protocelulares.

Publicaciones recientes:

RUIZ-MIRAZO, K. \& MORENO,A. (2013) «Synthetic Biology: challenging life in order to grasp, use or extend it». Fothcoming (in Biological Theory).

MAVELLI, F. \& RUIZ-MIRAZO, K. (2012): «Theoretical conditions for the stationary reproduction of model protocells». Integrative Biology (ya accesible online -- DOI: 10.1039/ c2ib20222k)-

Dirección electrónica: kepa.ruiz-mirazo@ehu.es

Alvaro Moreno es Cetedrático de Lógica y Filosofia de la Ciencia en el Departamento de Lógica y Filosofía de la Ciencia UPV/EHU y en el IAS Research Center for Life Mind and Society

Lineas de Investigación:

Filosofia de la Biologia, Sistemas Complejos, Origen de la Cognición

Publicaciones recientes:

RUIZ-MIRAZO, K., \& MORENO, A. (2012) «Autonomy in evolution: from minimal to complex life». Synthese, 185(1): 21-52.

ARNELLOS, A. \& MORENO, A. (2012) «How functional differentiation originated in prebiotic evolution». Ludus Vitalis XX(37), 1-23.

Dirección electrónica: alvaro.moreno@ehu.es 